\title{
Reliability of genomic prediction for German Holsteins using imputed genotypes from low-density chips
}

\author{
D. Segelke,${ }^{*} \dagger^{1}$ J. Chen,${ }^{* 1}$ Z. Liu,${ }^{\star 2}$ F. Reinhardt, ${ }^{*}$ G. Thaller, $\boldsymbol{\dagger}$ and R. Reents ${ }^{\star}$ \\ *Vereinigte Informationssysteme Tierhaltung w.v. (VIT), Heideweg 1, 27283 Verden, Germany \\ †Institute of Animal Breeding and Husbandry, Christian-Albrechts-University, 24098 Kiel, Germany
}

\begin{abstract}
With the availability of single nucleotide polymorphism (SNP) marker chips, such as the Illumina BovineSNP50 BeadChip (50K), genomic evaluation has been routinely implemented in dairy cattle breeding. However, for an average dairy producer, total costs associated with the $50 \mathrm{~K}$ chip are still too high to have all the cows genotyped and genomically evaluated. To study the accuracy of cheaper low-density chips, genotypes were simulated for 2 low-density chips, the Illumina Bovine3K BeadChip (3K) and BovineLD BeadChip (6K), according to their original marker maps. Simulated missing genotypes of the 50K chip were imputed using the programs Beagle and Findhap. Three genotype data sets were used to study imputation accuracy: the EuroGenomics data set, with 14,405 reference bulls (data set I); the smaller EuroGenomics data set, with 11,670 older reference bulls (data set II); and the data set of all genotyped German Holsteins, with 31,597 reference animals (data set III). Imputed genotypes were compared with their original ones to calculate allele error rate for validation animals in the 3 data sets. To evaluate the loss in accuracy of genomic prediction when using imputed genotypes, a genomic evaluation was conducted only for EuroGenomics data set II. Furthermore, combined genome-enhanced breeding values calculated from the original and imputed genotypes were compared. Allele error rate for EuroGenomics data set II was highest for the Findhap program on the 3K chip (3.3\%) and lowest for the Beagle program on the $6 \mathrm{~K}$ chip $(0.6 \%)$. Across the data sets, Beagle was shown to be about 2 times as accurate as Findhap. Compared with the real $50 \mathrm{~K}$ genotypes, the reduction in reliability of the genomic prediction when using the imputed genotypes was highest for Findhap on the $3 \mathrm{~K}$ chip (5.3\%) and lowest for Beagle on the $6 \mathrm{~K}$ chip (1\%) when averaged over the 12 evaluated traits. Differences in genome-enhanced breeding values of the
\end{abstract}

Received February 24, 2012.

Accepted May 23, 2012.

${ }^{1}$ These authors contributed equally to this study.

${ }^{2}$ Corresponding author: zengting.liu@vit.de original and imputed genotypes were largest for Findhap on the $3 \mathrm{~K}$ chip, whereas Beagle on the $6 \mathrm{~K}$ chip had the smallest difference. The low-density chip, $6 \mathrm{~K}$, gave markedly higher imputation accuracy and more accurate genomic prediction than the $3 \mathrm{~K}$ chip. On the basis of the relatively small reduction in accuracy of genomic prediction, we would recommend the BovineLD $6 \mathrm{~K}$ chip for large-scale genotyping as long as its costs are acceptable to breeders.

Key words: genomic evaluation, low-density chip, imputation, dairy cattle

\section{INTRODUCTION}

Since the release of the Illumina BovineSNP50 BeadChip (50K; Illumina Inc., San Diego, CA; Illumina, 2011b), genomic evaluation and selection have been implemented or are being implemented in an everincreasing number of countries for dairy cattle breeding (Liu et al., 2011; Lund et al., 2011; VanRaden, 2008). As a result, many potential AI bulls and bull dams around the world have been genotyped with the standard 50K chip (Wiggans et al., 2012). Because of its relatively high costs, widespread large-scale genotyping has still not been realized for average dairy producers in Germany. Thus, a clear demand for cheaper low-density chips exists among dairy producers and breeders. With the low-density chips, dairy breeders can screen their herds to identify genetically superior cows or bull calves for breeding. The $50 \mathrm{~K}$ chip can also be used to identify haplotypes and gene defects (VanRaden et al., 2011). Meanwhile, new chips of higher density or even complete genome sequencing are available for dairy cattle breeding. Dairy geneticists are challenged to work with even more diverse SNP chips (VanRaden et al., 2011).

The use of low-density marker panels for genomic evaluation based on, for example, the standard $50 \mathrm{~K}$ chip requires statistical methods for transferring genotype information from individuals genotyped at a higher density. Imputation can be performed to fill in SNP genotypes of a higher density reference panel from smaller SNP panel genotypes (Weigel et al., 2009; Druet et al., 2010; Zhang and Druet, 2010; VanRaden et al., 
2011). Several statistical methods for imputing SNP marker genotypes have been recommended (Browning and Browning, 2007; Druet et al., 2010; VanRaden et al., 2011). Imputation programs, such as Findhap version 2 (VanRaden et al., 2011) or Beagle version 3.3 (Browning and Browning, 2007, 2010), are relying on linkage based on family information or linkage disequilibrium (LD) based on population information (Scheet and Stephens, 2006; Browning and Browning, 2007). For the population-based imputation algorithms, Weigel et al. (2010) showed that using 4,000 SNP can provide approximately $95 \%$ of the predictive ability achieved using the real $50 \mathrm{~K}$ chip. By exploring both family and population information, Findhap was designed to combine population and pedigree haplotyping (VanRaden et al., 2011) to achieve higher accuracy of imputation. A study by Dassonneville et al. (2011) showed that using the Illumina Bovine3K BeadChip (3K; Illumina, 2011c) gave a mean imputation error rate of $5.5 \%$ for a Nordic countries data set and $3.9 \%$ for a French data set. Prediction of genomic EBV (GEBV) based on genotypes imputed with a smaller national reference data set gave an average loss of 0.05 in reliability of GEBV in the French study, whereas a loss of 0.03 was obtained for reliability of direct genomic values (DGV) in the Nordic study.

Chen et al. (2011) investigated the accuracy of genomic prediction for the $3 \mathrm{~K}$ low-density chip and found a loss in the reliability of genomic prediction for German Holsteins. Because of the relatively high cost of the $3 \mathrm{~K}$ chip in comparison with the $50 \mathrm{~K}$ chip, the low-density chip $3 \mathrm{~K}$ was not implemented in routine genomic evaluation in Germany. However, the same chip has been widely and routinely used in the United States since September 2010 (Wiggans et al., 2012). In September 2011, Illumina released a new low-density chip called the BovineLD BeadChip (Illumina, 2011a; Boichard et al., 2012; 6K), with more than 2 times more SNP on the chip as on the $3 \mathrm{~K}$ chip (Table 1 ).

The objectives of this study were to compare the imputation accuracy of the 2 programs Beagle and Findhap for both the 3K and 6K chips, and addition-

Table 1. Single nucleotide polymorphism markers used for this study

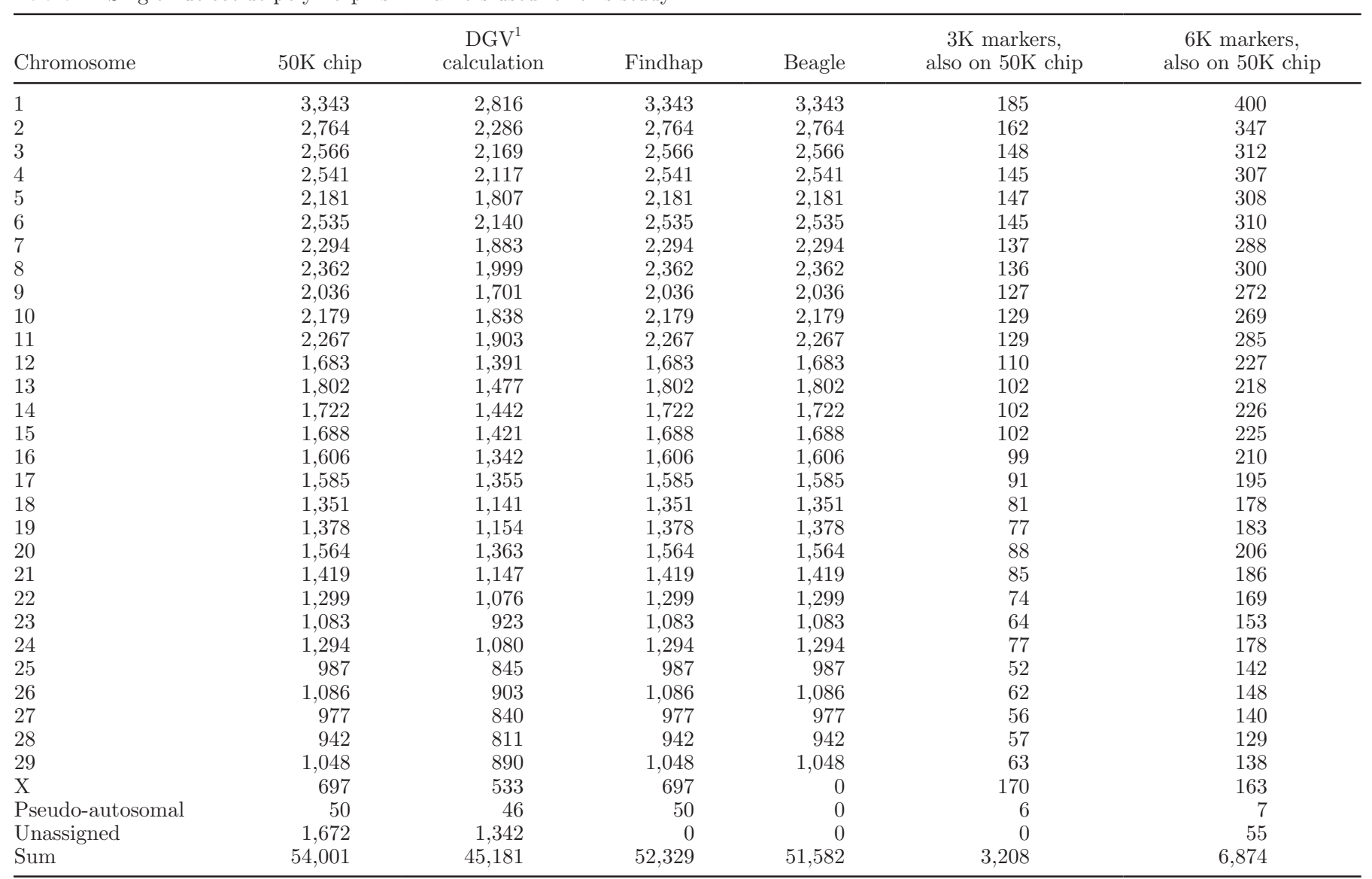

${ }^{1} \mathrm{DGV}=$ direct genomic value. 
ally to quantify the loss in reliability of genomic prediction when using imputed 50K genotypes for German Holsteins.

\section{MATERIALS AND METHODS}

\section{Genotype Data Sets for Imputation}

A total of 33,802 German Holstein animals from routine genomic evaluation in February 2011, genotyped with the standard $50 \mathrm{~K}$ chip, were selected for the $3 \mathrm{~K}$ and $6 \mathrm{~K}$ imputation study. Genotypes of $3 \mathrm{~K}$ and $6 \mathrm{~K}$ were simulated by using their original marker maps from Illumina for all the genotyped animals. For the commercial 3K chip, Illumina selected only 2,900 SNP out of its marker map, which contains 3,200 SNP. For the imputation study, 1,672 of the 54,001 SNP markers on the $50 \mathrm{~K}$ chip were excluded from the study because their chromosomal locations were not known, although 1,342 of the unassigned SNP markers have been used in routine genomic evaluation for German Holsteins (Liu et al., 2011). Table 1 shows the numbers of SNP on all chromosomes and those used by the 2 imputation programs. In total, Beagle (version 3.3; Browning and Browning, 2010) used 51,882, 6,594, and 3,032 SNP for the $50 \mathrm{~K}, 6 \mathrm{~K}$, and $3 \mathrm{~K}$ imputations. Because Findhap (version 2; VanRaden et al., 2011) can additionally consider SNP markers on sex chromosomes for genotype imputation, more SNP were able to be used: 52,329 , 6,763 , and $3,208 \mathrm{SNP}$ for the $50 \mathrm{~K}, 6 \mathrm{~K}$, and $3 \mathrm{~K}$ imputations, respectively. Three different genotype data sets (Table 2) were chosen to study the imputation accuracy and reliability of genomic prediction: a EuroGenomics (Lund et al., 2011) reference population with older bulls for late-measured traits such as days open (data set I), a EuroGenomics reference population (data set II), and all genotyped German Holstein animals (data set III). Validation bulls for late-measured traits for genomic prediction were older (data set I) than those for the traits in data set II; therefore, the reference population for genomic validation as well as for imputation also had older bulls for the late-measured traits. For validating the genotype imputation and genomic prediction, lower density $3 \mathrm{~K}$ and $6 \mathrm{~K}$ genotypes were simulated from the original $50 \mathrm{~K}$ genotypes of validation animals. The numbers of validation animals for the imputation accuracy and genomic prediction study were 534 Holstein bulls born between January 2002 and December 2002 for data set I and 1,374 bulls born between September 2003 and December 2004 for data set II. For data set III, all genotyped animals born after June 30, 2010, were considered, to simulate a routine imputation scenario in which the youngest candidates are genotyped with a low-density chip. Because genotyped dams and genotyped sires contribute equally for imputation, we also included genotyped female animals in data set III. For the genomic validation, the Black and White Holstein validation animals had to have their sire included in the reference population. The imputed $50 \mathrm{~K}$ SNP genotypes from the $3 \mathrm{~K}$ or $6 \mathrm{~K}$ chips were compared with the original genotypes of the validation animals to assess the accuracy of imputation. The imputation accuracy was defined as the allele imputation error rate (Druet and Georges 2010; Druet et al., 2010; Dassonneville et al., 2011; Chen et al., 2011), expressed as the ratio of incorrectly imputed alleles to all alleles. The allele error rate equals approximately one-half of the genotype error rate. The genotype error rate is equal to 1 - the genotype imputation accuracy. To compare accuracy between the Findhap and Beagle programs, sex chromosomes were not considered.

Additionally, we assessed the impact of the relationship of validation animals to the reference population on imputation accuracy by grouping the validation animals into 4 classes: neither sire nor maternal grandsire $(\mathrm{n}=29)$, only maternal grandsire $(\mathrm{n}=138)$, only sire $(\mathrm{n}=149)$, or both sire and maternal grandsire $(\mathrm{n}=$ 870) included in the reference population.

\section{Data Set for Genomic Validation Using the Imputed Genotypes}

To evaluate the loss in reliability of genomic prediction using imputed genotypes, a special genomic evaluation was conducted using genotype data set II. Liu et al. (2011) conducted a genomic validation study with real $50 \mathrm{~K}$ genotypes that was based on the same data set, which allowed a direct comparison of genomic prediction by using real and imputed genotypes. The SNP markers that were not imputed, such as unassigned

Table 2. Genotype data sets for the $3 \mathrm{~K}$ and $6 \mathrm{~K}$ imputations

\begin{tabular}{lll}
\hline Data set & Reference population & Validation population \\
\hline Data set I: EuroGenomics, old bulls & 11,670 EuroGenomics Holstein & 534 bulls (born between Jan. \\
& bulls (born before Jan. 2002) & 2002 and Dec. 2002) \\
Data set II: EuroGenomics, bulls & 14,405 EuroGenomics Holstein & 1,374 bulls (born between \\
& bulls (born before Sep. 2003) & Sep. 2003 and Dec. 2004) \\
Data set III: all genotyped Holstein animals & 31,597 animals (born before Jul. 2010) & 2,205 animals (born after Jul. 2010) \\
\hline
\end{tabular}


markers and SNP markers on sex chromosomes for Beagle, were set to missing in the DGV calculation (Table 1). For calculation of the DGV and GEBV, routine genomic evaluation procedures for German Holsteins were used, as described in Liu et al. (2011). Single nucleotide polymorphism effects were estimated with a BLUP model assuming trait-specific residual polygenic variance, and DGV were combined with conventional EBV or a pedigree index by using a selection index procedure to obtain GEBV for genotyped animals. Correlations between the DGV of imputed genotypes from the different scenarios were calculated for milk yield. Furthermore, correlations of the DGV of imputed genotypes with real 50K genotypes, deregressed EBV, and conventional EBV were calculated. From the April 2010 German national conventional evaluation, the following traits were evaluated: milk production (milk, fat, and protein yields), udder health as SCS, fertility (days open, nonreturn rate for 56-d heifer), and conformation (angularity, stature, chest width, teat length front, udder depth, and udder support), in terms of coefficients of determination and reliabilities of genomic prediction for the validation bulls. Additionally, differences in GEBV between the imputed and original $50 \mathrm{~K}$ genotypes were investigated. The differences were divided by genetic standard deviation of the respective trait to allow a direct comparison between traits. A $99 \%$ quintile range of the GEBV differences was calculated to exclude extreme values possibly caused by incorrect genotyping. All the calculations were conducted on a cluster of 64-bit Linux servers, each with multiple AMD Opteron processors (AMD, Sunnyvale, CA).

\section{RESULTS AND DISCUSSION}

\section{Accuracy of Imputation}

Computing time differed markedly between the Beagle and Findhap programs, with a clear advantage for Findhap. Because of the high computational demands of Beagle, only Findhap was used for the $3 \mathrm{~K}$ and $6 \mathrm{~K}$ imputations of the first and third data sets with 11,670 bulls and 31,597 animals, respectively, in the imputation reference population.

Table 3 shows genome-wide allele error rates of the $3 \mathrm{~K}$ and $6 \mathrm{~K}$ imputations for the data sets using the 2 programs, averaged over the validation animals. As the number of reference bulls or animals increased from data set I to III, the allele error rate decreased, showing that larger reference populations result in higher imputation accuracy. For the programs, the Findhap allele error rate declined about $1 \%$ from data set I to III with the $3 \mathrm{~K}$ chip; an almost equal reduction was seen for the $6 \mathrm{~K}$ data as well. The results clearly demonstrate that Beagle is more accurate than Findhap for imputing missing genotypes, although Beagle does not explore pedigree information in imputation. The difference in the error rates between Beagle and Findhap for the $3 \mathrm{~K}$ chip amounted to $1.7 \%$, whereas for the $6 \mathrm{~K}$ chip, the difference was $1.1 \%$. For Findhap, the difference in allele error rates between the $3 \mathrm{~K}$ and $6 \mathrm{~K}$ chips was $1.6 \%$ between data sets I and II and was 1.5\% for data set III. The decrease in allele error rate from the $3 \mathrm{~K}$ to $6 \mathrm{~K}$ imputation was less for Beagle than for Findhap, with a reduction of $1.0 \%$ for data set II. The significant differences in allele error rate between the $3 \mathrm{~K}$ and $6 \mathrm{~K}$ chips in our study confirmed the decision by Illumina to no longer sell the $3 \mathrm{~K}$ chip.

With an imputation error rate of $1.6 \%$ for Beagle and $3.3 \%$ for Findhap when using EuroGenomics data set II, our results for the $3 \mathrm{~K}$ imputation in this study were comparable with those obtained by Dassonneville et al. (2011). Mean imputation error rates were 4.0 and 2.1\% for the French and Nordic populations based on the EuroGenomics reference bull population, and higher imputation error rates, 5.5 and $3.9 \%$, were found when using their respective national reference populations.

Table 4 demonstrates that imputation accuracy depended on the relationship of validation animals to the reference population in all the investigated scenarios. When validation bulls had more relatives in the reference population, their missing genotypes tended to be filled in more accurately. For example, in cases when neither sire nor maternal grandsire (MGS) was in-

Table 3. Genome-wide mean allele error rates of the $3 \mathrm{~K}$ and $6 \mathrm{~K}$ imputations for Black and White Holsteins with a sire in the reference population

\begin{tabular}{llccc}
\hline & & & \multicolumn{2}{c}{$\begin{array}{c}\text { Mean allele error } \\
\text { rate (\%) }\end{array}$} \\
\cline { 3 - 5 } Program & Data set & $\begin{array}{c}\text { Validation } \\
\text { animals (no.) }\end{array}$ & $3 \mathrm{~K}$ & $6 \mathrm{~K}$ \\
\hline Findhap & Data set I: EuroGenomics, old bulls & 388 & 3.8 & 2.2 \\
Findhap & Data set II: EuroGenomics & 1,019 & 3.3 & 1.7 \\
Findhap & Data set III: All genotyped animals & 1,881 & 2.7 & 1.2 \\
Beagle & Data set II: EuroGenomics & 1,019 & 1.6 & 0.6 \\
\hline
\end{tabular}


cluded in the reference population, average allele error rate reached $5.5 \%$ when using Findhap for the 3K chip. When MGS was added to the reference population, allele error rate declined by $0.9 \%$. Similarly, a reduction in allele error rate by $1.8 \%$ for Findhap and the $3 \mathrm{~K}$ chip was achieved when the sire of the validation bull was a reference animal. Imputation was most accurate with the lowest error rate, $3.2 \%$, for the scenario of Findhap and the 3K chip when both the sire and MGS were added to the reference population. Even though Beagle did not explicitly explore familiar information in imputing missing genotypes, we did observe a higher accuracy of imputation with the sire or MGS included in the reference population, as found for Findhap. However, the improvement in imputation accuracy was much less evident for Beagle than for Findhap with regard to increasing the relatedness of the validation bulls to the reference population. Having more relatives included in the reference population resulted in a greater increase in accuracy for the $3 \mathrm{~K}$ chip than for the $6 \mathrm{~K}$ chip. As Druet et al. (2010) also found in their study, imputation had the highest accuracy when both the sire and MGS belonged to the reference population for all 4 scenarios, as shown in Table 4.

Figure 1 shows the mean allele error rates of Findhap per chromosome for the 3 data sets and the 2 chips. It can clearly be seen that the imputation accuracy differed between chromosomes, data sets, and chip densities. The imputation error rates tended to be higher for shorter than for longer chromosomes, which was more evident for the $3 \mathrm{~K}$ chip than for the $6 \mathrm{~K}$ chip data sets. Another reason for the smaller $6 \mathrm{~K}$ allele error rate was an increased concentration of SNP at the ends of the chromosomes. Additionally, high allele error rates, such as for chromosome 19, might be caused by map errors. Figure 2 compares allele error rates, by chromosome, between the 2 programs, Findhap and Beagle. The allele error rates for the Beagle $3 \mathrm{~K}$ chip were comparable with those for the Findhap $6 \mathrm{~K}$ chip. In contrast to the larger variation and stronger trend in error rates in the other scenarios, applying Beagle to the imputation of $6 \mathrm{~K}$ genotypes led to more uniform error rates across chromosomes.

\section{Accuracy of Genomic Prediction Using Imputed Genotypes}

Table 5 shows the correlations observed between the DGV of validation bulls in EuroGenomics data set II for milk yield. Findhap 3K had the lowest correlation with the real $50 \mathrm{~K}$ genotypes among all the studied scenarios. The DGV of scenarios Findhap $6 \mathrm{~K}$ and Beagle $6 \mathrm{~K}$ had equal correlations, 0.98 , with the real $50 \mathrm{~K}$ genotypes. The DGV correlation between Beagle $6 \mathrm{~K}$ and Findhap 6K was the same, 0.97, as between Beagle $6 \mathrm{~K}$ and Beagle 3K. Additionally, the correlation of DGV for the scenario with Beagle $3 \mathrm{~K}$ with deregressed EBV (DRP) and conventional EBV was 0.73 and 0.74, respectively. Equal correlations were found for the scenarios with Findhap $6 \mathrm{~K}$ and Beagle $3 \mathrm{~K}$. The DGV using the imputed genotypes of Beagle $6 \mathrm{~K}$ had equal correlations with DRP and EBV as did DGV using the real $50 \mathrm{~K}$ genotypes. Although the Beagle program did not consider the sex chromosomes in the imputation, it was more accurate, in terms of the correlations to DRP or EBV of the validation bulls, than the Findhap program, which explicitly took into consideration the SNP markers on the sex chromosomes. The correlation between the original 50K genotypes and Findhap 3K for milk yield was lower than that found by Wiggans et al. (2012), which can perhaps be explained by the smaller reference population in our study.

Table 6 reports coefficient of determination values from regressing the DRP of validation bulls on their GEBV by using the imputed $50 \mathrm{~K}$ genotypes. In comparison with the gain in coefficients of determination by genomics of the real $50 \mathrm{~K}$ genotypes, $\mathrm{R}_{\mathrm{GEBV}}^{2}-\mathrm{R}_{\mathrm{PI}}^{2}$ (Liu et al., 2011), genomic prediction using the imputed genotypes had a mean decrease in coefficients of determination across the 12 traits of $4.0 \%$ for the Findhap 3K scenario, $2.0 \%$ for the Beagle $3 \mathrm{~K}$ scenario, $1.4 \%$ for the Findhap $6 \mathrm{~K}$ scenario, and $0.8 \%$ for the Beagle $6 \mathrm{~K}$ scenario. For all the traits, the coefficient of determination value of genomic prediction based on genotypes imputed with Findhap 3K decreased the most. Especially for traits such as milk and fat yields, with a major gene, the reduction in coefficient of de-

Table 4. Genome-wide mean allele error rate for validation Black and White Holstein bulls, by their relationship to the reference population (data II)

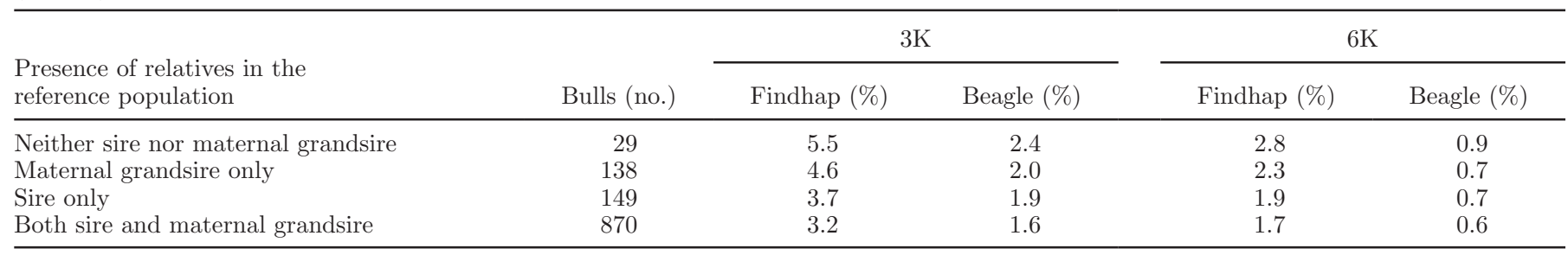




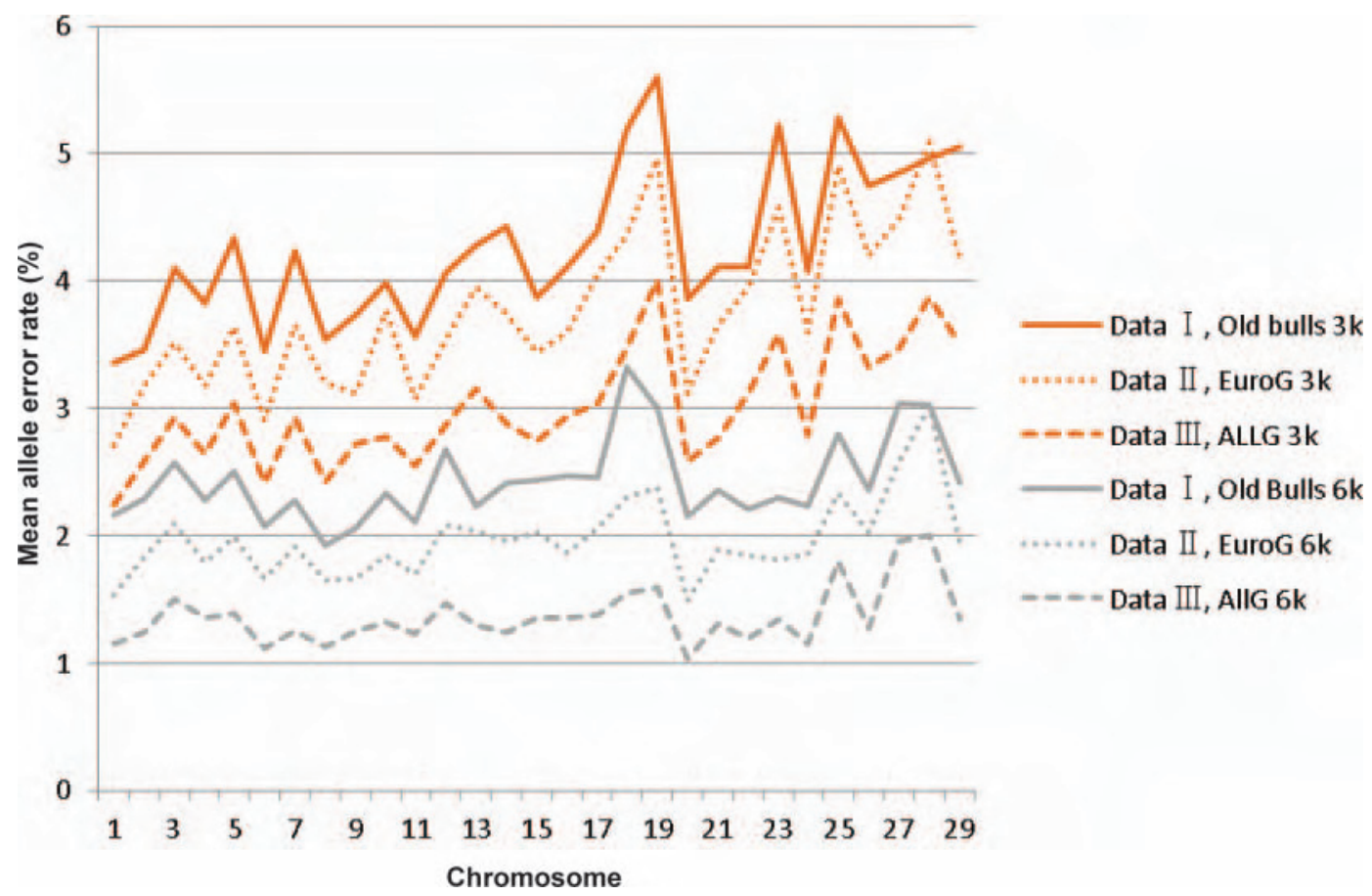

Figure 1. Mean allele error rate by chromosome for the 3 data sets when using the Findhap program. Color version available in the online PDF.

termination was high. In general, the loss in the coefficient of determination value was higher for traits with a higher accuracy of genomic prediction, such as SCS, stature, and udder depth. The imputation with Beagle gave a more accurate genomic prediction than the imputation with Findhap in both $3 \mathrm{~K}$ and 6K. Clearly,

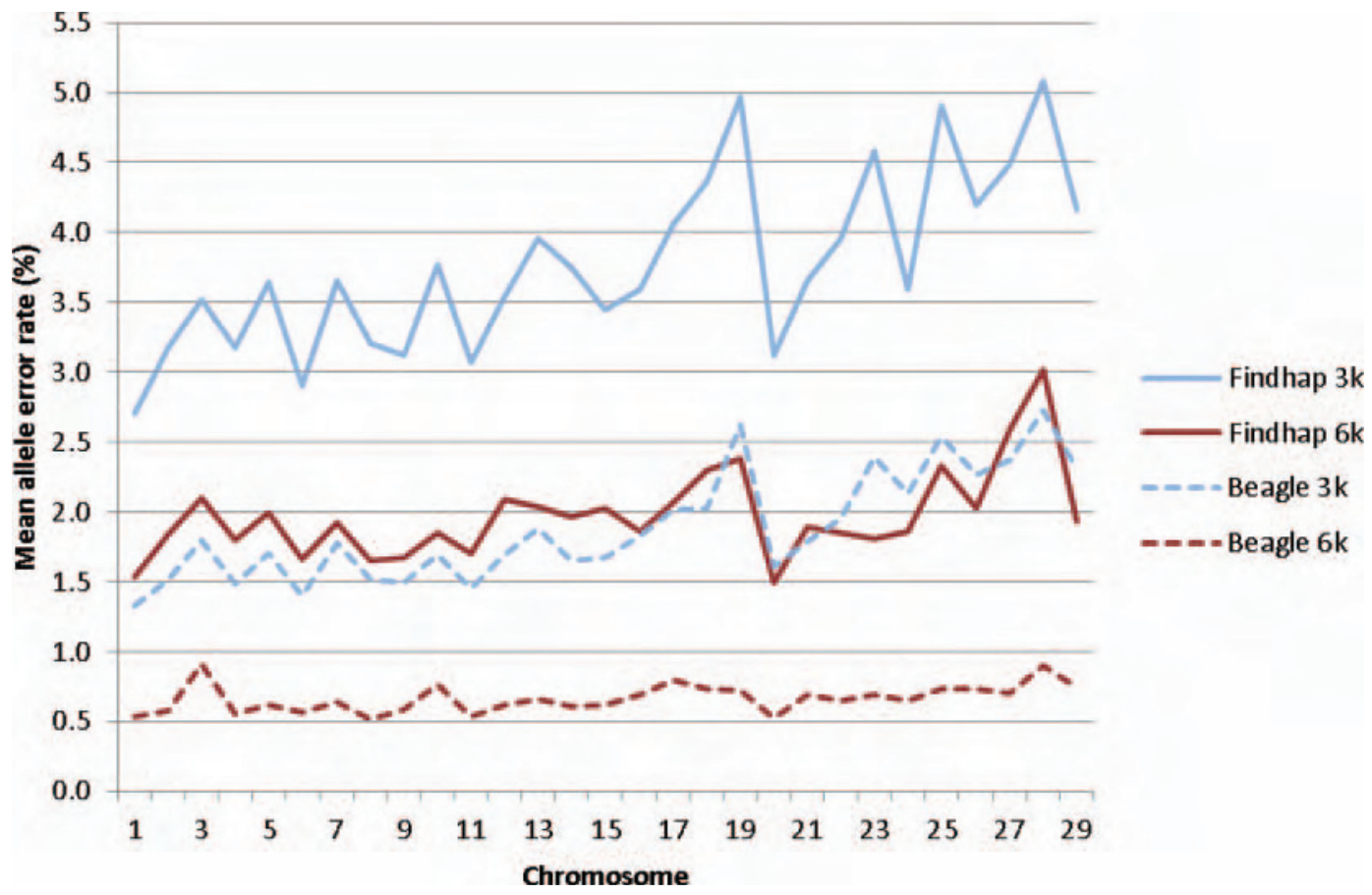

Figure 2. Mean allele error rate by chromosome when using EuroGenomics data set II. Color version available in the online PDF. 
Table 5. Observed correlations of direct genomic value for validation bulls in the EuroGenomics data (data set II) for milk yield

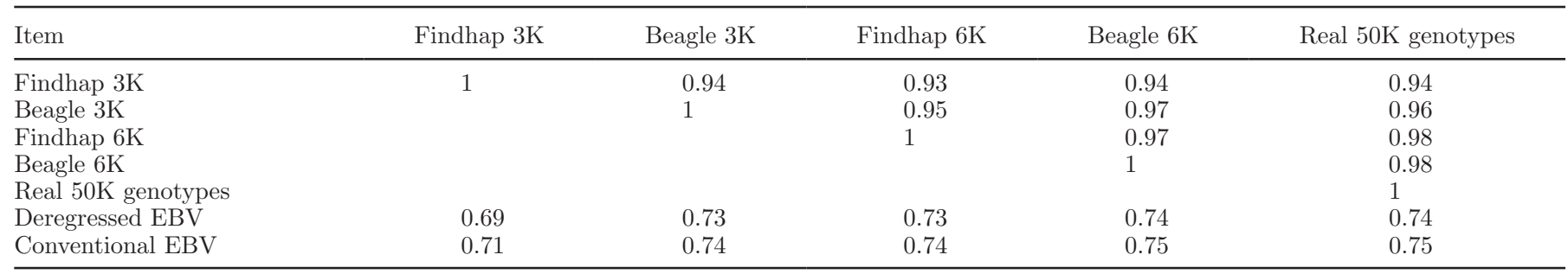

imputation with the $6 \mathrm{~K}$ chip gave, on average, more accurate genomic prediction than imputation with the 3K chip. However, imputation with Beagle $3 \mathrm{~K}$ yielded more accurate genomic prediction than did imputation with Findhap 6K for traits such as milk yield and angularity. Over all the traits, the decreases in coefficients of determination for Beagle $6 \mathrm{~K}$ were the lowest, except for the trait front teat length.

The reductions in reliability of genomic prediction when using the imputed 50K genotypes are shown in Table 7 . The gain in coefficient of determination value by genomics, $\mathrm{R}_{\mathrm{GEBV}}^{2}-\mathrm{R}_{\mathrm{PI}}^{2}$, was divided by the average reliability of conventional $\mathrm{EBV}$ of the validation bulls, and this value, $\left(\mathrm{R}_{\mathrm{GEBV}}^{2}-\mathrm{R}_{\mathrm{PI}}^{2}\right) /$ reliability, was considered the reliability gain attributable to genomics from using the real $50 \mathrm{~K}$ genotypes. Compared with the real $50 \mathrm{~K}$ genotypes, reliability of genomic prediction decreased by about $5.3 \%$ for scenario Findhap 3K, $2.6 \%$ for Beagle 3K, $1.9 \%$ for Findhap 6K, and 1\% for Beagle $6 \mathrm{~K}$, respectively. The reliability loss was highest, $8.2 \%$, for SCS when using Findhap 3K. For milk yield and days open when using Beagle $6 \mathrm{~K}$, no reliability reduction was observed. For some traits, such as milk yield, days open, nonreturn rate for 56-d heifer, or udder support, imputation of $3 \mathrm{~K}$ genotypes with Beagle gave better results than imputation of $6 \mathrm{~K}$ genotypes with
Findhap. For the conformation trait front teat length, the Findhap $6 \mathrm{~K}$ scenario gave a more accurate genomic prediction than the Beagle $6 \mathrm{~K}$ scenario.

Table 8 shows differences in GEBV of the validation bulls based on the original $50 \mathrm{~K}$ and imputed genotypes. The average and $99 \%$ quintile range of the differences were divided by the genetic standard deviation of the respective trait. It can clearly be seen that genomic prediction based on Findhap 3K gave the largest difference in GEBV based on the real 50K genotypes. Additionally, an overestimation of GEBV seemed to occur for most traits under this scenario. In contrast, average GEBV differences were close to zero for the remaining 3 scenarios, Beagle $3 \mathrm{~K}$, Findhap $6 \mathrm{~K}$, and Beagle 6K. Across all traits, the range in the $99 \%$ quintile was largest for Findhap 3K, followed by Beagle $3 \mathrm{~K}$ and Findhap $6 \mathrm{~K}$, and was smallest for Beagle $6 \mathrm{~K}$. When comparing our results for scenario Findhap 3K with those by Wiggans et al. (2012), we found that the imputation accuracy in both studies was comparable. However, Wiggans et al. (2012) did not find the differences in GEBV deviating from zero, as we experienced here. Furthermore, they obtained smaller ranges in the GEBV differences. These differences may be explained by our smaller data set for genotype imputation and genomic validation.

Table 6. Coefficient of determination values (\%), expressed as $R_{G E B V}^{2}-R_{P I}^{2}$, of the original $50 \mathrm{~K}$ genotypes and reduction in $R^{2}$ values when using the imputed $50 \mathrm{~K}$ genotypes

\begin{tabular}{|c|c|c|c|c|c|}
\hline Trait & $\begin{array}{l}\mathrm{R}^{2} \text { values using real } \\
50 \mathrm{~K} \text { genotypes }\end{array}$ & \multicolumn{4}{|c|}{ Reduction in $\mathrm{R}^{2}$ value } \\
\hline Fat $(\mathrm{kg})$ & 28.4 & 6.4 & 3.1 & 1.4 & 0.9 \\
\hline Protein $(\mathrm{kg})$ & 21.1 & 5.7 & 1.1 & 1.0 & 0 \\
\hline SCS & 31.2 & 5.8 & 2.9 & 1.5 & 1.1 \\
\hline Days open & 11.6 & 1.6 & 0.0 & 2.0 & 0 \\
\hline Stature & 32.5 & 6.4 & 3.4 & 1.9 & 1.6 \\
\hline Chest width & 20.6 & 2.8 & 2.0 & 1.2 & 1.2 \\
\hline Front teat length & 35.0 & 4.0 & 3.8 & 0.9 & 1.8 \\
\hline Udder depth & 36.8 & 6.3 & 4.9 & 2.4 & 1.8 \\
\hline Udder support & 16.5 & 1.1 & 0.4 & 0.5 & 0.1 \\
\hline Average & 23.9 & 4.0 & 2.0 & 1.4 & 0.8 \\
\hline
\end{tabular}

${ }^{2} \mathrm{NR}=$ nonreturn rate. 
Table 7. Reliabilities (\%), expressed as $\left(\mathrm{R}_{\mathrm{GEBV}}^{2}-\mathrm{R}_{\mathrm{PI}}^{2}\right) /$ reliability, of the original $50 \mathrm{~K}$ genotypes and the reduction in reliabilities when using the imputed $50 \mathrm{~K}$ genotypes

\begin{tabular}{|c|c|c|c|c|c|}
\hline Trait & $\begin{array}{l}\text { Reliability using real } \\
50 \mathrm{~K} \text { genotypes }\end{array}$ & \multicolumn{4}{|c|}{ Reduction in reliability } \\
\hline Milk (kg) & 35.1 & 6.6 & 1.1 & 1.8 & 0 \\
\hline Protein (kg) & 25.8 & 7.0 & 1.3 & 1.3 & 0 \\
\hline SCS & 43.6 & 8.2 & 4.1 & 2.2 & 1.5 \\
\hline Days open & 18.1 & 2.6 & 0.0 & 3.2 & 0 \\
\hline Stature & 37.0 & 7.3 & 3.8 & 2.1 & 1.8 \\
\hline Chest width & 26.6 & 3.6 & 2.6 & 1.6 & 1.6 \\
\hline Front teat length & 44.9 & 5.1 & 4.9 & 1.2 & 2.3 \\
\hline Udder depth & 46.9 & 8.0 & 6.3 & 3.1 & 2.2 \\
\hline Udder support & 23.3 & 1.6 & 0.5 & 0.7 & 0.1 \\
\hline Average & 31.3 & 5.3 & 2.6 & 1.9 & 1.0 \\
\hline
\end{tabular}

${ }^{1} \mathrm{NR}=$ nonreturn rate.

Equal regression coefficients of DRP on GEBV were obtained when using the imputed genotypes as when using the real $50 \mathrm{~K}$ genotypes. This indicates that using the imputed genotypes did not lead to biased GEBV. In reality, the reduction in genomic reliability from using the imputed $50 \mathrm{~K}$ genotype may not be as high as in this study because the reference population of the 50K chip was significantly larger than in this study and candidates with low-density genotypes tended to have more relatives genotyped with the $50 \mathrm{~K}$ chip.

\section{CONCLUSIONS}

We investigated the accuracy of genotype imputation from the low-density chips Illumina $3 \mathrm{~K}$ and $6 \mathrm{~K}$ to the standard 50K chip based on German Holstein animals. The 2 imputation programs, Beagle and Findhap, differed in computing time, with a clear advantage of Findhap for a large genotype population. However, for data set II and the 6K chip, the Findhap error rate was almost 3 times higher than the Beagle error rate. Allele imputation error rates depended on the size of the reference population, imputation programs, and chip density and on the relationship between reference and validation animals. Using the $6 \mathrm{~K}$ chip gave imputed genotypes that were twice as accurate as those using the $3 \mathrm{~K}$ chip. On the basis of the imputed genotypes, a genomic validation was conducted for scenarios with regard to the 2 chip densities and imputation programs. The accuracy of genomic prediction was reduced in comparison with that from the real $50 \mathrm{~K}$ genotypes. The scenario Findhap $3 \mathrm{~K}$ gave the least accurate genomic prediction, with an average reduction in reliability of $5.3 \%$ and the highest differences in GEBV. The most accurate genomic prediction using the imputed genotypes was the scenario Beagle $6 \mathrm{~K}$, with an average reduction in reliability of $1 \%$. We conclude, based on the results, that the low-density chip BovineLD $6 \mathrm{~K}$ could be used routinely for largescale genotyping.

Table 8. Mean and $99 \%$ quintile range of the genomic EBV difference between the original and imputed 50K genotypes of the validation bulls ${ }^{1}$

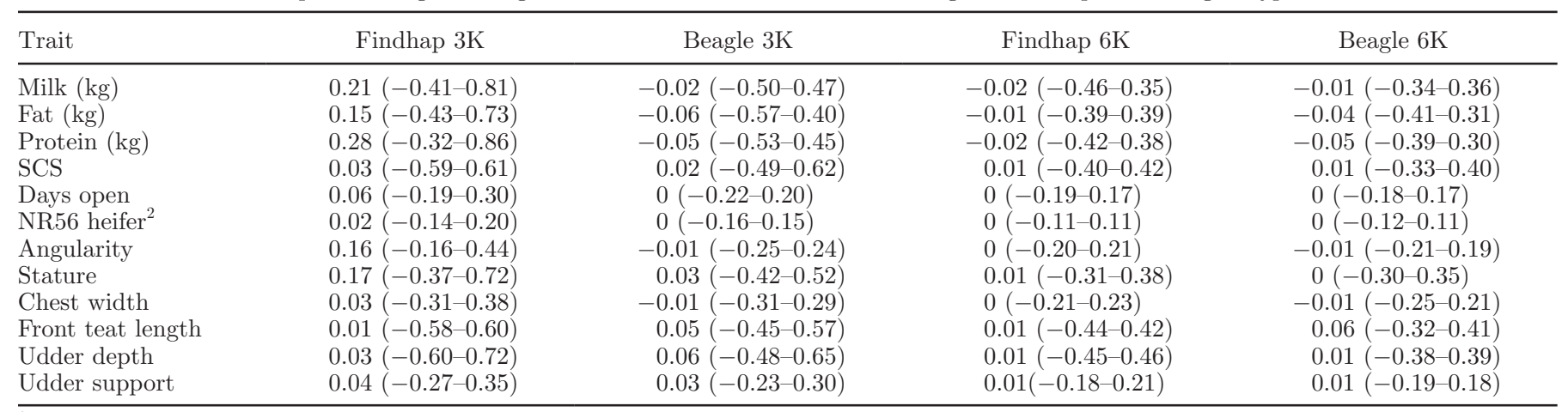

${ }^{1}$ All values were divided by genetic SD of the respective traits.

${ }^{2} \mathrm{NR}=$ nonreturn rate. 


\section{ACKNOWLEDGMENTS}

The German national organization Förderverein Biotechnologieforschung e.V. (FBF, Bonn, Germany) is thanked for financial support. The EuroGenomics consortium is kindly acknowledged for providing genomic data. We thank the University of Göttingen (Göttingen, Germany) for its support of J. Chen, as a postdoctoral fellow, for this project.

\section{REFERENCES}

Boichard, D., H. Chung, R. Dassonneville, X. David, A. Eggen, S. Fritz, K. J. Gietzen, B. J. Hayes, C. T. Lawley, T. S. Sonstegard, C. P. Van Tassell, P. M. VanRaden, K. A. Viaud-Martinez, G. R. Wiggans, for the Bovine LD Consortium. 2012. Design of a bovine low-density SNP array optimized for imputation. PLoS ONE 7:e34130.

Browning, S. R., and B. L. Browning. 2007. Rapid and accurate haplotype phasing and missing-data inference for whole-genome association studies by use of localized haplotype clustering. Am. J. Hum. Genet. 81:1084-1097.

Browning, S. R., and B. L. Browning. 2010. High-resolution detection of identity by decent in unrelated individuals. Am. J. Hum. Genet. 86:526-539.

Chen, J., Z. Liu, F. Reinhardt, and R. Reents. 2011. Reliability of genomic prediction using imputed genotypes for German Holsteins: Illumina $3 \mathrm{~K}$ to $50 \mathrm{~K}$ bovine chip. Interbull Bull. 44:51-54.

Dassonneville, R., R. F. Brondum, T. Druet, S. Fritz, F. Guillaume, B. Guldbrandtsen, M. S. Lund, V. Ducrocq, and G. Su. 2011. Effect of imputing markers from a low-density chip on the reliability of genomic breeding values in Holstein populations. J. Dairy Sci. 94:3679-3686.

Druet, T., and M. Georges. 2010. A hidden Markov model combining linkage and linkage disequilibrium information for haplotype reconstruction and quantitative trait locus fine mapping. Genetics 184:789-798.

Druet, T., C. Schrooten, and A. P. de Roos. 2010. Imputation of genotypes from different single nucleotide polymorphism panels in dairy cattle. J. Dairy Sci. 93:5443-5454.
Illumina. 2011a. BovineLD Genotyping BeadChip. Accessed Nov. 4, 2011. http://www.illumina.com/documents/products/datasheets/ datasheet_bovineLD.pdf.

Illumina. 2011b. BovineSNP50 Genotyping BeadChip. Accessed Nov. 4, 2011. http://www.illumina.com/documents/products/datasheets/datasheet_bovine_snp5O.pdf.

Illumina. 2011c. GoldenGate Bovine3K Genotyping BeadChip. Accessed Nov. 4, 2011. http://www.illumina.com/documents//products/datasheets/datasheet_bovine3k.pdf.

Liu, Z., F. Seefried, F. Reinhardt, S. Rensing, G. Thaller, and R. Reents. 2011. Impacts of both reference population size and inclusion of a residual polygenic effect on the accuracy of genomic prediction. Genet. Sel. Evol. 43:19.

Lund, M. S., S. P. W. de Ross, A. G. de Vries, T. Druet, V. Ducrocq, S. Fritz, F. Guillaume, B. Guldbrandtsen, Z. Liu, R. Reents, C. Schrooten, F. Seefried, and G. Su. 2011. A common reference population from four European Holstein populations increases reliability of genomic predictions. Genet. Sel. Evol. 43:43.

Scheet, P., and M. Stephens. 2006. A fast and flexible statistical model for large-scale population genotype data: Applications to inferring missing genotypes and haplotypic phase. Am. J. Hum. Genet. 78:629-644.

VanRaden, P. M. 2008. Efficient methods to compute genomic predictions. J. Dairy Sci. 91:4414-4423.

VanRaden, P. M., K. M. Olson, D. J. Null, and J. L. Hutchison. 2011. Harmful recessive effects on fertility detected by absence of homozygous haplotypes. J. Dairy Sci. 94:6153-6161.

Weigel, K. A., G. de los Campos, O. Gonzalez-Recio, H. Naya, X. L. Wu, N. Long, G. J. Rosa, and D. Gianola. 2009. Predictive ability of direct genomic values for lifetime net merit of Holstein sires using selected subsets of single nucleotide polymorphism markers. J. Dairy Sci. 92:5248-5257.

Weigel, K. A., G. de Los Campos, A. I. Vazquez, G. J. Rosa, D. Gianola, and C. P. Van Tassell. 2010. Accuracy of direct genomic values derived from imputed single nucleotide polymorphism genotypes in Jersey cattle. J. Dairy Sci. 93:5423-5435.

Wiggans, G. R., T. A. Cooper, P. M. VanRaden, K. M. Olson, and M. E. Tooker. 2012. Use of the Illumina Bovine3K BeadChip in dairy genomic evaluation. J. Dairy Sci. 95:1552-1558.

Zhang, Z., and T. Druet. 2010. Marker imputation with low-density marker panels in Dutch Holstein cattle. J. Dairy Sci. 93:54875494 . 